that a new series of experiments should be carried out on a smaller scale, with the object of finding out what other circumstances, in addition to double loading, are likely to cause these weapons to burst, and be a greater danger to friends than to foes. The destruction of the roo-ton gun is not calculated to increase confidence in this combination of steel and iron, especially when it is known that Armstrong and Woolwich guns are built up on almost exactly similar experiments. In addition to testing our own system in an exhaustive manner, guns by other makers should be subjected to exactly the same experiments, and if they yield better results, should be adopted into the service. We have lately seen that Sir William Palliser has subjected an old castiron gun, lined with wrought-iron tubes, on his well-known principle, to the test of double-loading with the most perfect success. Why should not the applicability of his system to guns of the largest calibre be tested? If, as it would appear, artillery officers are incapable of carrying out these experiments in a scientific manner, they should be assisted by outside talent, for the present state of uncertainty ought not to be tolerated for a day longer.

\section{VEGETATION UNDER ELECTRIC LIGHT}

$\mathrm{T}$ HE experiments which Dr. C. W. Siemens has made in growing plants with the illumination of the electric light, and which were laid before the Royal Society at its last meeting, were deservedly received with great interest. In a country where the State does so little in aid of the systematic prosecution of scientific inquiry, it is impossible not to feel something more than appreciative when men like Dr. Siemens bring to its aid the combined resources of wealth and technical knowledge. England is rich in splendid gardens equipped with every horticultural resource. But it is due to the fortunate circumstance that the possessor of such a garden has also paid great attention to the economic applications of electricity, that experiments have been made, on a scale never before attempted, which go a long way towards proving that, as far as vegetation is concerned, all the effects due to solar energy can be artificially produced.

Anything connected with electricity has a peculiar fascination for the public mind, and even in the discussion which took place at the Royal Society, there was not wanting the suggestion that there might be something-a little inscrutable, perhaps-due to the electrical origin of the source of light to which Dr. Siemens had subjected his plants, which exercised an important influence on the results. Such a feeling is of course likely to be still more prominent in the minds of those who have paid no special attention to the processes of plant-life, and who would feel that almost all the interest of the matter was gone if they were asked to eliminate the influence of electricity from it altogether. Yet, obviously, this must be the case directly Dr. Siemens's results are studied in relation with what has already been done in the same direction.

The great physical fact on which all vegetable, and therefore all other life, depends, is the breaking-up of atmospheric carbon-dioxide by the green colouring matter of foliage-chlorophyll, or leaf-green-under the influence of light. How the thing is done is not known; what is known is that it is accomplished by light, and that chlorophyll is the means or instrument by which light is able to effect the dissociation of carbon-dioxide which is the indispensable precursor to the building up by the plant of the various components of its tissues. The plant is in consequence an accumulator of energy, and when its substance is burnt this energy is liberated, and carbondioxide-amongst other things-is again produced.

Now the question which vegetable physiologists have been asking themselves since the beginning of this century is this :- Are these effects producible by light from any source if of adequate intensity, or, as Sachs inquired in 1865 , are they to be attributed to some quality specially inherent in solar light, and which cannot be artificially imitated? It is on this question that the real bearing of Dr. Siemens's experiments is of importance.

Closely connected with the conditions under which the rôte of chlorophyll is performed, are those necessary to its own production. Obviously as the plant grows, its chlorophyll cannot remain a constant quantity; and with some trifling exceptions which do not affect the matter, it may be laid down as an established fact that the same conditions which are essential for the activity of chlorophyll, are also favourable for its manufacture. But it is now known that chlorophyll may be developed under an amount of illumination which is insufficient to bring its functions into play. And this has been the difficulty which the problem has all along presented. In 1806 A. P. De Candolle experimented with the light of six Argand lamps; he found that this was sufficient to develop a green colour in etiolated leaves and also in young seedlings of mustard and cress, but he completely failed to obtain from perfectly healthy foliage any evolution of oxygen, and, therefore, any evidence that carbondioxide had been broken up. In 1860 Biot experimented with a powerful illuminating apparatus (with two Argand burners) which had been constructed for use in measuring an arc of meridian in Spain. This also failed, and it was suggested that the negative result of experiments with lamp-light was attributable to its poorness in rays of high refrangibility. The fact that these are most operative chemically has led many persons to think, on purely $\dot{a}$ priori grounds, that they must play the most effective part in the work done by chlorophyll. But repeated and most careful experiment has shown that this is certainly not the case. A long series of investigations, commencing with those of Daubeny (1836), and taken up successively by Draper (1844), Sachs (1864), and Pfeffer (I87I), have shown without a doubt that the yellow rays are as effective in vegetable nutrition as those of all the rest of the spectrum put together.

The first experiment with the electric light in connection with vegetation was made by Hervé-Mangon in 1861 . He succeeded by means of it in developing chlorophyll in young seedlings of rye, but he did not succeed in demonstrating any chlorophyllian activity by the evolution of oxygen. He found, however, that the electric light possessed one of the characteristic properties of sunlight in producing heliotropism in plants exposed to it. While it is found that the less refrangible rays of the solar spectrum undoubtedly play the most important part in the chemical work which is essential to plant life, the more refrangible rays exercise what may be described as 
a mechanical control. When grown in badly lighted places plants become elongated or "drawn up," while when freely illuminated, the rays of high refrangibility moderate this undue growth in length. Plants also, as is well known, bend towards a source of light; this is caused by the growth of their stems being checked on the illuminated side, which become consequently shorter. If they are grown behind red glass they are indifferent to one-sided illumination, because the rays which would affect their growth unequally are cut off. Hervé-Mangon showed that this heliotropic effect could be produced by the electric light as well as by that of the sun, and this was a fresh point gained.

In 1866 Wolkoff found that seedlings of cress grown in the dark became green after eight hours' exposure to the flame of a Bunsen burner made luminous by sodium carbonate. This was a crucial experiment as far as showing that the production of chlorophyll was independent of the so-called chemical rays of the spectrum. A few years later Prillieux completed the demonstration of the competence of light from artificial sources to perform all that the sun could do as regards the dissociation of carbon-dioxide by showing in M. Jamin's laboratory at the Sorbonne that oxygen was evolved by a water plant whether illuminated by the electric light produced by a magneto-electric machine, the Drummond light, or even gas-light of sufficient intensity.

This is the point at which the subject has remained for Dr. Siemens to take it up. He has worked on a far larger scale than is possible in a laboratory experiment, and has substituted for the sun a little sun of his own. To quote the account in the Times, "an electric centre of light equal to 1,400 candles placed at a distance of two metres from growing plants appeared to be equal to average daylight at this season of the year." As far as the experiments went, not merely were all the effects which from a horticultural point of view might be expected from daylight reproduced by the electric light, but, by making the latter supplement the former, double work was extracted from the plants, and the growth of vegetation under the prolonged summer of northern latitudes was artificially imitated. The observation of HervéMangon was also extended, and it was found that the electric light was competent to produce all the mechanical effects of daylight such as bringing about the re-erection of the foliage of plants which during night-time exhibit the phenomenon of sleep. Seedlings of mustard which had never seen daylight were quite as green and vigorous as those which had never been submitted to the artificial light. The same result was shown by the foliage of carrots and those which had been illuminated naturally by day and artificially by night had leaves which were palpably taller and greener than those which, whether from natural or artificial sources, had only enjoyed a smaller amount of illumination. Dr. Siemens promises a more extended series of experiments, and, to give the matter a complete trial, it would certainly be desirable to compare the results during longer periods of growth when the plants were more thoroughly thrown on their own resources. It must be remembered that seedlings grow to a large extent at the expense of the materials stored up in the seeds, and the same thing is true of the foliage produced from fleshy roots like those of the carrot. In both cases the plant is mainly feeding on itself. The real test would be to take some short-lived annual and see if it would run through its course with illumination from an artificial source alone, and how the actual weight of plant-tissue manufactured would compare with that produced under an equivalent exposure to sunlight.

With regard to the action of artificial light on flowers, some caution is requisite in drawing conclusions. The Daily News of March 6 states that "Dr. Siemens exhibited to his audience a pot of tulips in bud, which the electric light brought into full bloom in some threequarters of an hour." This sounds almost as wonderful as the mango-trick of the Indian jugglers. As a matter of fact the tulips were not, properly speaking, in bud; the flowers were fully developed, and were simply unexpanded, and all that they did when exposed to the electric light they would equally have done in the dark if exposed to a temperature as high as that in the immediate vicinity of the lamp. It is well known that the flowers of tulips are very sensible in this respect to even small changes of temperature, and the heat given off by the lamp used by Dr. Siemens is so considerable that he proposes, as one advantage of its use in horticulture, to employ it "to counteract the effect of night frost," and "to promote the setting and ripening of fruit in the open air." Dr. Siemens also showed a fully developed rose produced under the influence of the electric light, which compared strikingly with an unopened bud which had not bad the same advantage. It might be suggested that here again the influence of temperature would require to be carefully eliminated. Sachs has found that, I ruvided the foliage of plants is fully exposed to daylight, the flowers will be perfectly developed and will even mature seed in total darkness. And in the case of bulbs wien the reserve of nutriment required for the evolution of flowers is already prepared, with proper conditions of temperature and moisture, the flowers will also be developed in the total absence of light. Even in woody plants this may be accomplished; the white lilac which is used for bouquets in the spring, is supplied from bushes of the ordinary kind, which are dug up in the autumn and forced the following year in perfectly dark buildings. The only difference which ever appears to occur is illustrated in this particular instance in the non-development of the colour of the flowers.

What may be the practical applications of the electric light in horticulture is still a question for the future. Dr. Siemens finds that illumination by it enables plants to sustain increased stove-heat without collapsing. This is an interesting point, because it brings out clearly the mode in which plants are naturally adjusted to exposure to sunlight without suffering injury. Light increases transpiration, and transpiration prevents the temperature of plant tissues rising to a point at which they would suffer from "scorching." The hope that the electric light might aid investigation as to the mode of formation of alkaloids such as quinine in the plant will scarcely perhaps lead to any practical result. The researches of Howard, on the one hand, show that the Cinchona alkaloids are not formed in the leaves, and making their appearance as they do in the bark, which is progressively thrown off by desquamation, they may with reason be regarded as excretions by which the plant gets rid of 
superfluous nitrogen. On the other hand Broughton has shown that the action of light leads to the degradation of the Cinchona alkaloids in the bark into other compounds, and the same fact has been pointed out with regard to Sirychnos.

Its use in horticulture will in all probability be limited to the gardens of the wealthy, where there will be no difficulty in employing it to make plants grow at double their normal speed if that is ever practically found worth while. It may also perhaps be found available in accelerating and supplementing the effect of our tardy and penurious sunlight in ripening fruit. But the scientific interest of its present application must rest mainly on the fact that the cycle of the transformation of energy engaged in plant life is now complete, and that, starting from the energy stored up in vegetable fuel, we can run through the changes from heat to electricity, and thence to light, which we now know we can store up in vegetable fuel again.

\section{MOORE'S ORNITHOLOGICAL TABLES}

British Birds Systematically Arranged in Five Tables, showing the Comparative Distribution and Periodical Migrations, and giving an Outline of the Geographical Range of 376 Species. By G. Peter Moore, F.L.S. Captain R.S.L.M., late 3rd Hussars. Imp. 4to. (London: Van Voorst, I 879.)

CAPT. MOORE'S object in publishing this work is not very apparent, and he can hardly be said to assign sufficient reasons for it when he states that he submits it

"To those persons, without the care or leisure to become students in ornithology, to whom an easy method of obtaining a general knowledge as to the comparative distribution of our birds may be an object of interest, and who, when 'the time of the singing of birds is come, and the voice of the turtle is heard in our land, feel a desire to know something of the nature of these welcome visitants, and the periods of their arrival, and whither they go when they leave us."

At the same time we willingly bestow on his labours that "friendly scrutiny" which he bespeaks for them, "should they fall into the hands of practical ornithologists." In the absence of any other motive we venture to believe that Capt. Moore, being laudably bent upon improving his own knowledge of the geographical distribution of the many kinds of birds which it pleases some people to dub "British," has been at the great pains of drawing up these tables for his private use, and then, conscious of the enormous toil which it has cost him to obtain his results, has felt desirous of offering them to the public in the hope of saving others from the trouble of doing the like labour over again. The question whether the results reached are worth the trouble expended on them is one that it would be ungenerous to discuss, for we rather hold that no honest labour is wasted, even if the benefit that accrues from it be not immediately evident, and of honest labour there is here enough. Besides, the stuciy of ornithology is in this country followed by so large a number of persons, and by them in so many different ways, that it is impossible for any critic of a work which certainly strikes out a new line of treatment, if not of investigation, to predict whether it may not find a considerable body of admirers, or many at least whom it will profit. We think, indeed, that the latter is more than probable, for we are sure that the amount of information which our author's pages convey, and that in the most concise form, is vastly greater than such as is possessed by most of those who are justly considered British ornithologists. It remains, of course, for them to use it, but if they will not, the blame is not with Captain Moore. He does his best to bring the water to the horses, since it is not for him or any other author to take the horses, or other less noble animals, to the water ; and, if they will not drink it, it is their own fault, for the water is drawn from good springs, and though here and there it would have been the better for a little more filtering, analysis shows that it is wholesome taken altogether.

The "Tables" are a marvellous example of the printer's skill, and reflect the greatest credit on the wellknown establishment of Messrs. Taylor and Francis. We have to raise but one objection to them, and that is the occasional employment of what we may perhaps call "florid gothic" type-or, if we might be excused a Hibernicism, we should say of "black" letter which is not black. We profess no acquaintance with the technicalities and mysteries of the printer's art, but merely from the general reader's point of view, a good strong "clarendon" for attracting the eye is worth all the "gothic" founts that were ever invented, save only those of the most antique pattern, and in them, by the way, some of the letters are often with difficulty distinguished. Apart from this, the Tables have evidently been drawn up with a wonderful amount of patience. We have put them to a pretty severe trial, and may congratulate Capt. Moore on coming out of it with flying colours. To say that they do not in all cases adequately express the part which any particular species plays in our fauna is no real objection, for such must be the inevitable consequence of the tabulation of facts so multitudinous as those furnished by the biography of birds. It is impossible by schedules alone, without the addition of footnotes, apostilles, or some other contrivance of the like kind, to convey by any means that simple tabulation affords a correct notion of the peculiarities of distribution of such species as Savi's Warbler or the common Crossbill. These are undoubtedly extreme instances, but there are many others only less impatient of tabular treatment, and it must be remembered that we now know, or ought to know, enough of our birds to be assured that each species has its own particular lifehistory, which cannot possibly be served after a Procrustean method without the risk-nay, certainty-of undergoing some deformation. In a few instances Capt. Moore seems to have gone astray, as in the case of the Golden Plover, which is marked as being a regular but rare summer-migrant in the Færoes, Iceland, and Spitsbergen, and occurring in North America from lat. $35^{\circ}$ to $70^{\circ}$, though a note of doubt is appended to the last statement. There seems to be no evidence at all that the true Charadrius pluvialis is ever found in North America, and it certainly cannot be said to be rare in the Færoes, while its appearnce in Spitsbergen is anything but regtilar. So, too, with the Great Auk, we have the old story repeated of its being an inhabitant of the "Polar Regions," though that story has been refuted again and again; but we suppose that to the end of time the fable 